\title{
Effect of Management Behaviours and Environmental Dynamics on Market Orientation Behaviours among Botswana's Small Service Firms
}

\author{
Olumide Olasimbo Jaiyeoba (Corresponding author) \\ Department of Marketing, Faculty of Business, University of Botswana, Botswana \\ E-mail: olujaiyeoba@yahoo.com
}

Received: July 11, 2013 Accepted: August 2, 2013 Published: December 25, 2013

doi:10.5296/bms.v4i2.4951 URL: http://dx.doi.org/10.5296/bms.v4i2.4951

\begin{abstract}
Market orientation has emerged as a significant antecedent of organizational performance and is presumed to contribute to the long term success of a firm. While all firms are strongly influenced by their external environmental, small and medium sized firms may be more influenced by their own tangible and intangible management behaviours as well as environmental dynamics. The growing number of academic studies on market orientation and mixed findings they have reported complicate the efforts among managers and academics to identify the real antecedents of this construct. The results of this study shows that there is a positive association between top management emphasis, interpersonal connectedness, market turbulence, competition and market orientation behaviours of small service firms. Centralization component of management behaviours among small service firms was however found to have positive relation with market orientation attitudes of small service firms. This contrast with extant findings in developed economies. This study thus explicate some new insights and questions on this important strategic direction.
\end{abstract}

Keywords: Management Behaviours, Environmental dynamics, Market Orientation, Small Service Firms and Botswana 


\section{Introduction}

While all firms are strongly influenced by their external environment,small and medium sized firms may be even more influenced by their own internal culture. The smaller firms are less bureaucratic and more a reflection of their own specific leadership and internal circumstances. These obstacles remain comparatively understudied (Whittington and Whipp,1992).Few studies have responded to the conclusion of Jaworski and Kholi (1993) that " it seems desirable to assess the role of additional factors in influencing the market orientation of an organization". This study,thus lend credence to Jaworski and Kholi's(1993) proposition that studies should be conducted to identify typology of barriers of market orientation.

The aim of this paper is to focus on the internal and external dynamics to market orientation in Botswana and specifically to identify the principal types of management behaviour and environmental dynamics which affect the extent to which small service firms can successfully achieve market orientation. This study does not attempt to develop an exhaustive list of management behaviours and environmental dynamics amongst small service firms in Botswana, but rather to identify and review principal management behaviours and environmental dynamics that appear to inhibit or encourage market orientation. This study thus make an important contribution to achieving a better understanding of the real problems that managers face in achieving market orientation.

\subsection{Background Information of the Study}

The purpose of this paper is to empirically investigate the antecedents of market orientation among Botswanas'small service firms.Many small service organizations experience difficulties in becoming market oriented.Most studies on small service organizations have been conducted in developed economies. Extant market orientation research has mostly addressed the antecedents of market orientation in organizations in developed countries (Avlonitis \& Gounaris,1999;Jaworski \& Kholi,1993;Kirca,Jayachandran, \& Bearden,2005).It is imperative that we study structures,systems, and behaviours of small service firms, most especially in developing economies, because they have the potential to redefine the interaction between firms and society(Zahra et al.,2000). Furthermore, research on antecedents of market orientation in small service is important because a market orientation is likely to improve performance and productivity. Market orientation has a positive effect on organizational performance across various private contexts (Kirca et al.,2005;Rodriguez Cano, Carrillat, \& Jaramillo,2004) and in public contexts, where political mechanisms rule in addition to or in lieu of economic mechanisms (Cervera,Molla, \& Sanchez,2001; Shoham,Ruvio, Vogoda-Gadot, \& Schwabsky,2006).However, antecedents that affect market orientation, especially in developing economies, most especially in Botswana, have seldom been addressed.Thus, this research is consistent with calls by (Kholi \& Jaworski, and Kumar,1993; and Narver \& Slater,1990), that the robustness of any model of market orientation should be studied using other organization types in order to gain valuable insights, most especially in small service organizations in developing economies. This study is guided 
by these and other calls and critiques. The result of this study thus contribute to our overall knowledge of factors facilitating and impeding market orientation in the small service firms, most especially in Botswana.

\subsection{Research Objectives}

This proposed research attempts to significantly contribute to the theory and practice of market orientation by testing the hypotheses envisaged, and there by achieving the following objectives:

1) To investigate the effect of management behaviours (Senior management characteristics, organisational characteristics, and Interdepartmental Dynamics) on the level of market orientation of SMMEs service firms in Botswana.

2) To determine if environmental dynamics (Competition, Market turbulence, Technology, and General Economy) has significant effect on the level of market orientation of Botswana's SMMEs service firms.

\subsection{Significance of the Study}

This study contributes to the service literature in three ways.Firstly, it enhances our knowledge of the management behaviours and environmental dynamics of market orientation in service organizations whereas extant research has mainly investigated the consequences of market orientation.Secondly,it also increases our understanding of structures,systems, and behaviours of service organizations in the small service sector in Botswana. Thirdly, this study point at the importance of change capacity factors for market orientation in a service industry,most especially in the small firms delivery services in Botswana..Essentially, it shows, that the level of control over quality and improvements in key processes-a factor largely overlooked in earlier empirical research in market orientation- which is crucial for becoming market oriented.

\section{Literature Review}

Antecedents to market orientation refer to organizational factors that enhance or impede the implementation of the MO concept (Deshpande, 1999).It is widely assumed that managers can improve market orientation by emphasizing market-oriented attitudes, behaviours, and reward systems; tolerating acceptable risk; communicating effectively; embracing change; and providing opportunities for staff advancement while avoiding formalization, centralization, and interdepartmental conflict (Kirca et al.,2005). This study intends to assess the effects of five theorized market-orientation antecedents identified by Jaworski and Kholi (1993): reward systems, risk attitudes, interdepartmental conflict, formalization, and centralization. In a study conducted by Kohli and Jaworski (1993) on several US firms, corroborating with the literature on the subject area, provide an explicit list of three main antecedents to MO, senior management factors (role of senior management), interdepartmental dynamics (formal and informal interactions and relationships among an organization's departments), and organizational systems (organization wide characteristics 
relating to structure). Thus for a proper implementation of MO in business firms, senior managers must be convinced of its value and communicate this commitment to junior employees, and develop positive attitudes towards change (Deshpande, 1999). Several propositions pertaining to antecedents have not only being proposed by Kholi and Jaworski(1990), but they have being empirically validated by them. Top management reinforcement of the importance of market orientation is likely to encourage employees to track changing markets, share market intelligence, and be responsive to market needs. Kholi and Jaworski (1990), also argued that if top management demonstrates a willingness to take risks and accept occasional failures, junior managers are more likely to propose and introduce new offerings in response to changing customer needs. Likewise, Kholi \& Jaworski,(1990), concluded that, if top management is risk averse and intolerant of failures, subordinates are less likely to focus on generating or disseminating market intelligence or responding to customer needs.

Several related streams of research, including (Narver and Slater,1990) and (Kholi and Jaworski,1993), posit that market orientation is affected by interdepartmental connectedness and interdepartmental conflict.Essentially,interdepartmental conflict is likely to inhibit communication among departments (Ruekert \& Walker,1987; cited in Kholi and Jaworski,1993),thereby hampering market orientation.Kholi \&Jaworski,(1990),concluded that the more interdepartmental connectedness experienced in an organisation, the more likely employees are to exchange market intelligence and respond to it in a concerted fashion. Pulendran et al.,(2000), concluded that if MO contributes to superior business performance, then what internal factors cause some firms to go down that route while others do not? Narver and Slater,(1990);Jaworski and Kholi,(1993);Harris and Piercy,(1998),postulated that the identification of the principal management behaviours involved is vital to organizations that seek to become market oriented.

Raaij and Stoelhorst (2008) have also extensively studied antecedents of a MO, from an implementation perspective as they provide clues of how to develop MO in a firm. They clearly distinguish between external antecedents like environmental factors that stimulate a firm's adoption of a MO, and internal antecedents like organizational factors that enable the adoption of a MO concept. Other external antecedents available in the literature are market dynamism and competitive intensity (Kohli and Jaworski, 1990). They add that in a stable business environment, few adjustments to the marketing mix are needed, requiring slow level of MO. Internal antecedents empirically proposed and tested in the literature include the three organizational processes that foster a MO: recruiting and selecting customer focused individuals, market oriented training, and market oriented reward and compensation systems (Ruekert, 1992, cited in Raaij and Stoelhorst, 2008).

Jaworski and Kohli (1993) also advanced eight antecedents: top management emphasis on MO, top management risk aversion, interdepartmental conflict, interdepartmental connectedness, degree of formalization, degree of decentralization, degree of departmentalization, and reliance on market-based factors for evaluations and rewards 
systems. Kirca et al. (2005) in their meta-analysis of the eight antecedents of Jaworski and Kohli(1993), sum them up to form the most three important antecedents commonly used in modern literature on MO: top management emphasis, interdepartmental conflict and connectedness, and reward systems. These equally harmonise naturally with those earlier espoused by Deshpande (1999). Thus, conclusions about antecedents of MO provide critical levers for implementing and or increasing MO within a firm, critical for small service firms in Botswana for which this study seek to address. Previous studies have identified both external and internal antecedents to market orientation. External antecedents are environmental factors beyond the organisation while internal antecedents are factors existing within the organisation.

Various internal antecedents have been proposed and tested for association with market orientation. These include Senior Management characteristics such as market oriented training (Ruekert 1992; Liu \& Davies 1997), formal marketing education (Horng \& Chen 1998;Harris 2000), top management emphasis on market orientation (Jaworski \& Kholi 1993), and top management risk aversion. Internal antecedents also include Organisational characteristics (Centralisation,formalisation,Political Behaviour, Interdepartmental Conflict and Connectedness, as well as market based reward system (Jaworski \& Kholi, 1993).A number of these antecedents are expected to be relevant to market orientation in Botswana.

External antecedents are environmental factors beyond the organisation. Examples of external antecedents previously found to be significantly related to market orientation are market turbulence (Jaworski \& Kholi 1993) and competitive intensity (Avlonitis \& Gounaris 1999), as well as technology. Market turbulence can be defined as to how quickly customers can change preferences in a particular period of time. When market turbulence is low, organisations have reduced pressure to adopt a market orientation stance given the stability in the market and or the lack of effective competition for customers (Zebal \& Goodwin 2011).Market turbulence thus means the changing degree of consumers " needs and preference. The firm does not have necessity to adjust marketing mix strategy in order to respond to consumers' behaviour efficiently when consumers' needs and preferences are stable, so firm might be less market oriented organisation. To the contrary, if the degree of consumers' preferences is unstable , and the firm does not respond to consumers 'needs timely, performance may be decreased Kholi \&Jaworski,(1990);Narver \&Slater,(1994),concluded that firm will become market oriented, when consumers' preference is variable. Technology turbulence means changing degree of technology in products and service. The studies of Kholi \&Jaworski,(1993) as well as Slater \& Narver (1994),concluded that the industry using stable technology depends on market orientation more because this industry has low probability that it can gain competitive advantage through technological advancements.Kholi\&Jaworski (1993),found that the lesser the extent of technological turbulence, the greater the extent of market orientation-performance relationship. A greater level of market orientation helps firms in effectively dealing with the challenges arising due to technological turbulence. For instance, the failure in commercialization of new technologies, and the costs associated with these activities can be minimized if firms can 
integrate the technological knowledge with the knowledge of customers'expectations.Such integration, however,requires a great deal of understanding of not only what customers expect and what the competition has to offer,but also a great deal of coordination between different departments. The company, under greater competitive environment, could become more market oriented than a lesser competitive one (Kholi\&Jaworski,1990;Slater\&Narver,1994).They thus concluded that the greater the extent of competitive intensity, the greater the extent of market orientation-performance relationship.

The external environment in which organizations operate is complex and constantly changing; a significant characteristic of the external environment is competition (Wood et al.,2000).Organisations that recognize the presence and intensity of competition have a greater tendency to seek out information about customers for the purpose of evaluation and to use such information to their advantage (Slater \& Narver,1994).Chen and Miller,(1994),concluded that the level of competitive intensity determines a firm's choice of strategic actions and responses.Chen and Miller (1994), thus postulated that the likelihood of a response depends on visibility of the competitive actions and the rivals' ability to gauge the consequences of a competitive action. Recognition of the threat from competition drives organizations to look to their customers for better ways to meet their needs, wants, and thereby enhances organizational performance (Wood and Bhuian,1993).Jaworski and Kholi,(1993),thus noted that it becomes important to not only have a high level of competitor orientation, but also a high level of customer orientation to better understand customer expectations, and a high level of inter-functional coordination to effectively respond to challenges of the market place. Accordingly, when competition is perceived as a threat by the organization, there is a greater tendency to adopt a market orientation (Wood et $a l ., 2000)$. There has been a long tradition of support for the assumption that environmental factors influence the effectiveness of organizational variables (Appiah-Adu,1998). Indeed, several studies have investigated the association between different environmental factors and established the effects of moderating influences on organisational variables (e.g., Slater \& Narver(1994);Jaworski \& Kholi,1993;Greenly,1995 and Han et al.,1998).Researchers have argued that firms should monitor their external environment when considering the development of a strong market-oriented culture (Kholi \& Jaworski,1990).

In general terms, $\mathrm{MO}$ is understood as a response to a specific part of the external environment that is composed of consumers and competitors (Kholi and Jaworski,1990; Narver and Slater,1990). While a substantial academic literature has examined MO,this work is limited with respect to small businesses.Specifically, previous research has yet to consider empirically the relationship between small business MO and environmental uncertainty. This study, therefore lend credence to research direction suggested by Atuahene-Gima et al.,(2005) that to expand the contingency view of MO,external environmental factors need to be examined,as this will advance extant marketing literature by explaining why some firms are able to adopt responsive and proactive market orientation more effectively than others. Due to resource constraints, smaller businesses are viewed as especially vulnerable to 
environmental uncertainty. Pelham and Wilson (1996), assert that to maximize their flexibility and responsiveness under conditions of environmental uncertainty requires small businesses to have a higher level of MO.The findings of this study reinforce the view of MO as a dynamic construct which can help to explain the relationship between small businesses and environmental uncertainty.

The role of environment as an important contingency factor has been long espoused by organisational scholars (Dess and Beard,1984).Dess and Beard,(1984),concluded that the external environment puts constraints on a firm's strategic actions and the benefits a firm can derive from those actions. A greater level of environmental dynamism and complexity requires that firms be more responsive to these changes.Bamford et al.,(1999),concluded that external environment poses additional challenges for small businesses as small businesses do not always have resources to counter the external pressures.

While the body of research on consequences of Market orientation is large, relatively little research has investigated its antecedents. Thus, the aim of this research is not only to focus on the consequences of market orientation amongst Botswana's small service firms, but more specifically to identify the principal types of management behaviour which affect the extent to which a company can successfully achieve market orientation. This study does not however intends to develop an exhaustive list or typology of management behaviours and environmental dynamics, but rather to review principal management behaviours that inhibit or encourage market orientation in Botswana.The study therefore makes an important contribution to achieving a better understanding of the real problems that managers of small service firms face in achieving market orientation and customer focus in Botswana.

Sivaramakrishnan et al.,(2008) cited in Awwad and Agti,(2011),concluded that extant research typically stops at identifying the antecedents of market orientation, while the interactions and correlations among those antecedents are not typically studied.Thus, antecedents remain an important task for future research. A better understanding of these antecedents would certainly help managers in their efforts to implement market orientation. Although, Kholi and Jaworski framework includes a comprehensive set of antecedents, other frameworks, such as Narver and Slater's, have placed less emphasis on identifying antecedents, Aviv et al.(2005).Voola et al.,(2003) concluded that while market orientation plays a key role in organizational profitability,practitioners require a clear understanding of its antecedents in order to implement this concept.Based on their review of the literature,Jaworski and Kholi (1993), included three sets of MO antecedents. The first focuses on top management factors and includes the top managers'emphasis on customer needs.MO is developed when a firm emphasizes the importance for managers to track market changes, share market information with others, and be responsive to market needs.In addition,top managements's willingness to take risks drives the firm towards MO.Such willingness is necessary because responding to changing markets often requires the introduction of new products. Risk taking is intrinsic to innovation and is related to a firm's knowledge creation capability (Rogers,1995).Jaworski and Kholi (1993) proposed that risk 
aversion depresses market orientation by discouraging the development and the implementation of strategies and acceptance of reasonable risks.Sitkin \& Pablo,1992, thus postulate that risk is a multidimensional construct that comprises perceptions of outcome uncertainty, outcome likelihood, and potential outcome range. The second set of antecedents pertains to interdepartmental dynamics, including interdepartmental conflict and connectedness.Conflict can harm MO by reducing communication flows, thus limiting the coordination and implementation of effective firm-wide responses to gathered and disseminated information. Burgess and Nyajeka ,(2007),concluded that interdepartmental conflict refers to disagreements and struggles for control between functional areas of the firm. Jaworski and Kholi (1993), hypothesized that it reduces market orientation by hindering information flow and cross-functional cooperation.Smith,Dugan,Peterson, \& Leung,(1998),notably concluded that where hierarchy and embeddedness are high, interdepartmental conflicts are discouraged and disputes typically are mediated by senior managers. This is consistent with Cano et al.,(2004), who argued that cultural embededness and hierarchy should have a beneficial effect on organisational structures,processes, and information sharing, so that interdepartmental conflict would be minimized and not have a negative effect on market orientation. The meta-analysis of Kirca et al., (2005) confirmed the bivariate relations of interdepartmental conflict and market orientations, but no effect was observed when multivariate antecedents relations were assessed. However, constructive interdepartmental connectedness can facilitate the dissemination of information.

The third set of antecedents include organisational systems:centralisation,formalization, and firm reward systems.Centralization involves the participation in and delegation of decision making responsibilities throughout the firm. Jaworski and Kholi (1993) theorized that centralization aids implementation but hinders market orientation by reducing intelligence generation, dissemination, and response design. Hierarchy is expected in LICs. Centralization has been prominent in market orientation theory but its hypothesized negative effects were assessed using rigorous multivariate meta-analysis techniques (Kirca et al.,2005).Burgess and Nyajeka,(2007), analogously postulated that embeddedness within organisational structures,preferences for hierarchy, and reward systems, common characteristics in LICs,potentially counter its negative effects on market orientation. Formalization is defined as the degree to which roles, authority, communications, norms, sanctions, and procedures are defined by rules (Jaworski and Kholi,1993).Jaworski and Kholi (1993) theorized that formalization would have two effects on market orientation. First, it would inhibit market orientation by enmeshing people in rules and procedures that discourage acquiring and sharing information and participating in developing market -oriented policies and procedures. Second, it would encourage implementing market-oriented strategies.However,Jaworski and Kholi, (1993), were unable to confirm the hypothesized links and neither could Kirca et al.,(2005), in their meta analysis.Kuada and Buatsi (2005) did not find significant links between formalization and market orientation in Cote DÍvoire or Ghana. Burgess \&Nyajeka.,(2007) concluded that formalization is not incompatible with LICs cultural priorities.Thus,they concluded that the presumed rationale underlying the hypothesized 
negative effects of formalization on market orientation does not obtain in LICs.Accordingly,people in LICs prefer to rely on written rules in working relations (Licht,Goldschmidt,\& Schwartz,2005; Smith et al.,1998).Burgess and Nyajeka.,(2007),concluded that previous research, though scant, supports this contention. Centralization and formalization could thus, limit flexibility and the communication and utilization of information across departments, thereby inhibiting the development of MO.Market-oriented reward systems refers to employee performance and evaluation systems that focus on market-based measures of performance.Kholi and Jaworski,1990;Ruekert,1992, concluded that market- oriented reward systems increase market orientation by rewarding employees for objective outcomes, such as (market share or customer satisfaction survey result) and behaviours such as (speed of customer service, effective handling of customer complaints).Chelariu,Quattarra, \& Dadzie,(2002);Kuada \& Buatsi,(2005); and Kirca et al.,(2005) concluded that reward systems have a consistent and strong positive effect on market orientation in African LICs.This study intends to investigate the hypothesized propositions amongst service SMME firms in Botswana.

\section{Conceptual Development and Hypotheses}

From a focused and sustained meta-analytical review of seminal literature on market orientation,stretching from 1990-2010,the researcher distilled a conceptual framework in figure 1 below upon which this study is based.

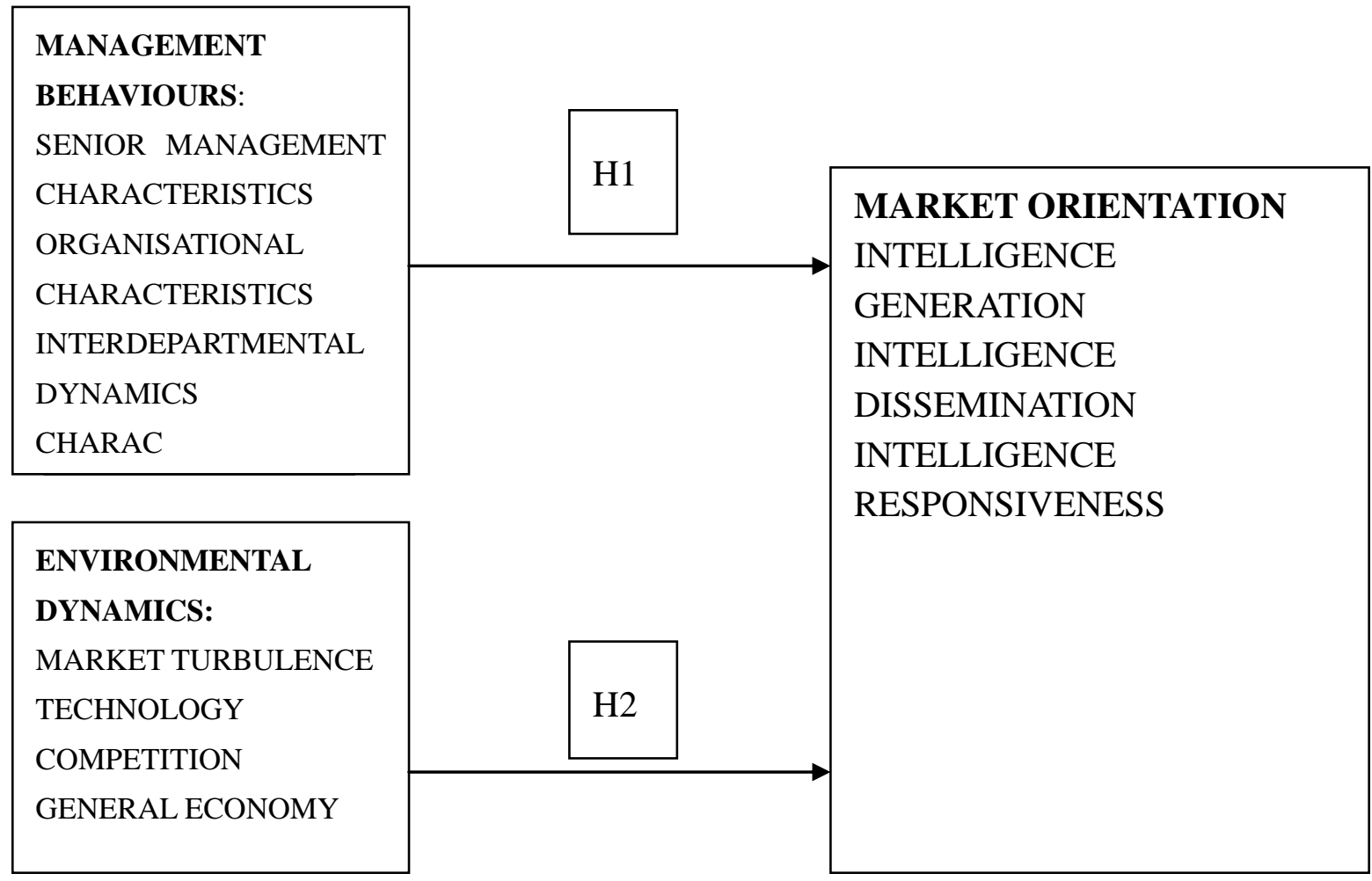

Figure 1. Management Behaviours And Environmental Dynamics Of Market Orientation(Adapted From Kholi\&Jaworski 1993) 
The MARKOR scale adopted provides a refined direction for the researcher and thus serves as a basis of this empirical study. The framework depicts 2 conceptual hypotheses tested in this empirical study,focused on measuring the management behaviours and environmental dynamics of overall market orientation behaviour of small service firms in Botswana.

After a focused search and scrutiny of both empirical and theoretical literature on market orientation,the researcher managed to generate the following scientific hypotheses, that the study seek to test as evident on the framework.

Jaworski and Kholi (1993) identified three categories of internal antecedents to MO (senior management factors,interdepartmental dynamics, and organizational systes), as well as four categories of external antecedents to MO (market turbulence,technology,competition,and general economy) adapted from extensive stream of extant MO literature.

These antecedents act as management behaviours and environmental dynamics of MO,resulting in some organizations being more market oriented than others.

H1: For small service firms in Botswana, the management behaviours are associated with the level of market orientation.

Hla: The senior management characteristics are associated with the level of market orientation of small service firms in Botswana.

H1b: The organizational characteristics are associated with the level of market orientation of small service firms in Botswana.

H1c: Interdepartmental dynamics (such as interdepartmental connectedness and conflict) are associated with the level of MO.

H2: For small service firms in Botswana environmental dynamics are associated with the level of $M O$.

H2a: The level of market turbulence of small service firms in Botswana is associated with the level of market orientation.

H2b: The level of technological turbulence of small service firms in Botswana is associated with the level of market orientation.

H2c: The level of competition is associated with the overall market orientation behaviour of small service firms in Botswana.

$H 2 d$ : The strength of the economy is associated with the level of market orientation.

\section{Research Methodology}

The study employed a snowball sample of managers and business owners in the small service firm domain within Gaborone and its environs.The reason for opting for non-probability rather than probability sampling was that the sampling frame of the key informants was not available. In addition,the study was exploratory in nature in order to improve the 
understanding of organizational market orientation behaviour in Botswana context. The final pool of small service firms to whom questionnaires was sent totaled 400.Eventually,only 249 (constituting over $60 \%$ response rate) usable questionnaires were returned by the respondents. The questionnaire was pretested prior to collecting data and respondents were asked to identify items they found unclear,ambiguous or confusing. As a result of the pretest,minor adjustments were made to the questionnaire. Data was collected between mid July 2012 to Mid October 2012.The majority of the respondent personnel were managers, accounting for about $50 \%$ of the total.This suggests that most respondents were sufficiently experienced to be able to provide meaningful response to broader policy issues relating to market orientation.

After comparing the responses of the early and late respondents, on a number of characteristics,no significant difference was found suggesting that the sample is free from response bias.The sample size and the response rate are consistent with related studies.

The questionnaire and scale measures (MARKOR Scale) were adopted from Kholi \& Jaworski,(1993) constructs.The items in the questionnaire were measured with the aid of a Five point Likert type Scale.The management behaviours were measured by items adopted from Jaworski \& Kholi,(1993).Environmental dynamics were adopted from Jaworski \& Kholi,(1993) and Gray et al,(1998) respectively. Reliability analysis was conducted on all the multi items scales to check the internal consistency of the scales. This study adopted a cut off of 0.5 for Cronbach's Coefficient following Nunnally (1988).Using 0.5 as the cut off is not without precedent.It has been adopted in related studies (Blankson \& Stoke,2002;Blankson \& Cheng,2005).Reliability results have been presented in table1.The coefficient alpha values for intelligence generation,intelligence dissemination or interfunctional coordination, and intelligence responsiveness or taking action are 0.63,0.60, and 0.55 respectively,indicating that the MARKOR scale developed by Kholi and Jaworski (1993) was also a reliable instrument for measuring market orientation in Botswana.The coefficient alpha values of 0.73 for top management emphasis and 0.88 for centralization also confirmed the reliability of Kholi and Jaworski's (1993) scale items for data collection in Botswana.Similarly,other scales including market based reward system,interpersonal conflict,interpersonal connectedness,market turbulence,technological turbulence adapted from Kholi and Jaworski (1993) produced coefficient alpha values of 078,0.62,0.81,0.53 and 0.63 respetively,thus indicating that these scales were also reliable for data collection in Botswana.

\section{Results and Discussion}

Table 1. Antecedents (internal and external) of Market Orientation 


\begin{tabular}{|c|c|c|c|c|c|c|}
\hline \multicolumn{7}{|c|}{ Dependent variable: Overall Market Orientation } \\
\hline \multicolumn{2}{|c|}{ Independent variables } & B & S.E. & $\operatorname{EXP}(B)$ & Sig. & ( $\beta)$ \\
\hline \multicolumn{2}{|c|}{ Top Management } & 1.904 & 0.658 & $6.714 *$ & .004 & 5.71 \\
\hline \multicolumn{2}{|c|}{ Centralization } & 0.618 & 0.310 & $1.855^{* * * *}$ & .046 & 0.86 \\
\hline \multicolumn{2}{|c|}{ Interpersonal Connectedness } & 0.610 & 0.364 & $1.840 * * *$ & .094 & 0.84 \\
\hline \multicolumn{2}{|c|}{ Market turbulence } & 1.093 & 0.350 & $2.983^{*}$ & .002 & 1.98 \\
\hline \multicolumn{2}{|c|}{ Competition } & 0.874 & 0.306 & $2.398^{*}$ & .004 & 1.40 \\
\hline \multicolumn{2}{|c|}{ Constant } & -8.859 & 1.541 & $0.000^{*}$ & .000 & \\
\hline $\begin{array}{c}\text { Cox \& Snell R } \\
\text { Square(Adjusted) }\end{array}$ & 0.234 & & & & & \\
\hline $\begin{array}{c}\text { Nagelkerke R } \\
\text { Square }\end{array}$ & 0.312 & & & & & \\
\hline
\end{tabular}

Significant at the $0.01,0.05$ level, and 0.1 level as *,**, and *** respectively.

Top management emphasis, Centralization, Interpersonal connectedness, market turbulence, and competition have been found to be significantly associated with overall market orientation and explain $\mathbf{2 3 \%}$ (Table 1) in the level of market orientation behaviours of service small firms in Botswana.Formalization,political behaviours,interpersonal conflict,risk aversion of top managers, as well as technological turbulence,level of general economy are not significantly associated with market orientation principles of small service firms in Botswana.

Top management emphasis was found to be positively and significantly $(\boldsymbol{\beta}=\mathbf{5 . 7 1 , p}<\mathbf{0 . 0 1})$ associated with market orientation ehavior of small service firms in Botswana. This finding is consistent with Kholi \& Jaworski (1990);Jaworski \& Kholi (1993);and Pulendran et al.,(2000).Top managers shape the values and orientation of an organization (Webster 1988).Therefore, without the emphasis of owners/managers, it would be unlikely to commit necessary resources for small businesses to pursue market oriented activities.Thus,owner-managers of Botswana's service small firms must provide the resources and strategic direction for small businesses to operate on market oriented principles. The development of market orientation should start with leadership from the owner-managers of small service business in Botswana. This study findings lend substantial support to Narver \& Slater's (1990) results, confirming that top management emphasis has a significant association with market orientation ehavior of small service firms in Botswana. Kholi \& Jaworski(1993),concluded that top management reinforcement of the importance of a market orientation is likely to encourage individuals in the organization to track changing markets, share market intelligence with others in the organization, and be responsive to market needs. This finding also lend credence to Dadzie and Winston (2002), finding in Nigeria and Kenya, in which they found out that top management emphasis on market orientation provides insight into how marginal conditions impact on the applicability of market orientation philosophy in Sub Saharan African Countries. Thus, hypotheses 1 \& 1 a are partially 
supported in this study.

The regression analysis results, contrary to dominant findings in extant market orientation literature, indicate that centralization amongst sampled small service firms in Botswana is positively and significantly associated $(\boldsymbol{\beta}=\mathbf{0 . 8 6}, \mathbf{p}<\mathbf{0 . 0 5})$, with market orientation. Thus, this finding partially support Hypotheses $\mathbf{1} \& \mathbf{1 b}$ in this study. In other words, centralized organizational structure is cherished among Batswana's small service businesses studied. While scholars (Kholi\&Jaworski,1990); Ruekert, (1992); Narver\&Slater, (1990); Webster,(1988), advocate that organizations must be less centralized to enhance market orientation cultures of firms. Small businesses viewed centralization as crucial for the development and implementation of greater market orientation in their organizations. These results may not be surprising in that, small business deliberation of the market place involves informal, unplanned activity that relies on intuition and energy of the owner-manager to make things happen (Stokes \& Blackburn, 1999).This research findings thus contrast with Kholi \&Jaworski(1993) findings which suggested that organizational dimension such as centralization tend to hinder the generation and dissemination of information and the design of organizational response. The Botswana study's findings amongst small service firms is consistent however with Burgess \& Nyajeka's (2007) study in Zimbabwe, in which they found out that centralization has positive and significant association with market oriented behaviours. Cano et al.,(2004), thus concluded that people in cultures that emphasize embeddedness and hierarchy are more willing to surbodinate their own goals to those of others to engage in market oriented behaviours. Burgess \& Nyajeka (2007), concluded that embeddedness within organizational structures,preferences for hierarchy, and reward systems,common characteristics in developing economies, potentially counter its negative effects on market orientation.

Interpersonal connectedness was found to be significantly and positively associated $(\boldsymbol{\beta}=\mathbf{0 . 8 4}$, $\mathbf{p}<\mathbf{0 . 1})$ with market orientation effort of small service firms in Botswana. Interdepartmental connectedness is the extent of formal and informal contact amongst employees across the departments of an organization (Zebal et al., 2011).This research finding is consistent with streams of findings in contemporary market orientation literature. Jaworski \& Kholi (1993) concluded that interpersonal connectedness fosters an interdependency within the organization and encourages employees to act in a concerted manner in the processes of knowledge generation and knowledge utilization. Hypotheses 1\&1c are therefore partly supported in this study of service small firms in Botswana. Interpersonal conflict was however found not to have significant association with market orientation of small service firms. This research findings corroborates Pulendran et al., (2000) findings in which he concluded that interdepartmental connectedness contributes significantly to higher levels of market orientation and helps a firm to act in a more consistent manner across the organization towards their customers.

Market turbulence was also found to be significantly and positively associated $(\boldsymbol{\beta}=\mathbf{1 . 9 8}$, $\mathbf{p}<\mathbf{0 . 0 1}$ ) with market orientation behaviours of small service firms in Botswana. This provides 
support for the propositions of Jaworski \& Kholi, (1990) and Narver \& Slater, (1990) and is in agreement with their findings. Wood \& Bhutan, (1993), concluded that external environmental factors are perhaps more influential in determining the level of market orientation. Jaworski \& Kholi (1993) asserted that organizations that operate in the more turbulent markets are likely to have to modify their products and services continually in order to satisfactorily cater to customers' changing preferences. They then suggested that the businesses operating in more turbulent markets are likely to have a greater need to be market oriented. Pulendran et al., (2000), argued that it is imperative that organizations are highly market oriented in conditions of market turbulence. They thus suggested that a focus must be placed on listening and responding to customer's needs and a failure to adapt will render an organization competitively unstable.Appiah-Adu (1997) augmented this by arguing that the influence of market orientation on performance depends on the level of market turbulence. Hypotheses 2 \&2a are therefore partly supported in this study of service small firms in Botswana. Pulendran et al., (2000) analogously postulated that once customers begin to have the opportunity to switch preferences, market turbulence increases and organizations are forced to adopt a strategy of market orientation if customers are to be retained.

The benefits afforded by a market orientation are greater for organizations in a competitive industry compared with organizations operating in less competitive industries. The level of competitive intensity of small service firms in Botswana was found to be positively and significantly associated $(\boldsymbol{\beta}=\mathbf{1 . 4 0}, \mathbf{p}<\mathbf{0 . 0 1})$ with market orientation ehavior of small service firms. Kholi \& Jaworski, (1990), concluded that in the absence of competition, an organization may perform well even if it is not very market oriented. This is because customers are stuck with the organization's products and services. In contrast, under conditions of intense competition, customers have many options, and organizations that are not market oriented will probably lose out. This study is consistent with Avlonitis and Gounaris (1999) findings in which they observed that organizations that considered competitive intensity as market factor found a strong positive relationship between competition and market orientation. Wood and Bhuian, (1993) concluded that the greater the perceived competition, the greater the tendency to adopt a market orientation. This findings concurred with Han et al, (1998), in which they observed that organizations in highly competitive environments focus more on learning about competitors, which is a key aspect of market orientation. Hypotheses 2 \&2c are partly supported in this study. Thus, Botswana's small service business need to elicit competitive actions in keeping customers with the company.

\section{Conclusion and Recommendation}

Extant market orientation literature point to the importance of management behaviour and environmental dynamics in improving levels of market orientation. The limitation of current theory is the acute paucity into relationship of management behaviours and environmental dynamics amongst small service firms in developing economy, most especially in Botswana. This gap in the body of knowledge is surprising given that broader body of literature attest to 
the important role internal and external antecedents play in market orientation behaviour and organizational performance improvement. The findings of this study lead to a number of interesting implications for theorists and practitioners. As such, this study contributes to empirical verification by explicating management behaviours and environmental dynamics as critical antecedents of market orientation. The research findings thus suggest that the scale items captures the construct of Market orientation amongst Botswanas'service oriented small business environment effectively.

The study findings generally resonate with the results of Jaworski and Kholi (1993), as well as Narver and Slater,(1990).It also offers one more support for the robustness of Jaworski and Kholi's (1993) model. However, a closer look into the results reveals some interesting insights. Firstly, the influence of top management traits on market orientation is fairly stable across diverse context. All replications have been consistent about these relationships (Bhuian,1998;Kuada and Buatsi,2005).That is, top management is a crucial factor for an organization to be market oriented. Secondly, organizational factors, both structural and interpersonal, as determinants of market orientation are not completely decisive. This study found interpersonal conflict and formalization not having any roles in the market orientation model. Thirdly, environmental factors play a critical role in the market orientation behaviours of small service firms in Botswana. The findings of this study indicate that higher levels of market dynamism and competitive intensity tend to result in an increased emphasis on market oriented behaviours or strategies amongst small service firms in Botswana.

The findings of this study support the call for more targeted training interventions where operations are core to the survival of many small businesses. Skills transference by means of training and outcome-based education, using interactive workshops, which are based on action learning and role playing, are recommended. As part of government's initiative to empower and enhance the skills of small business owners, policies should encourage the development of specific functional skills of which market orientation behaviour is central to sustainability.

Based on the findings of the study, leadership of Batswana small service firms should stress on providing the required resources, encouraging the sharing of market based ideas through suggestion schemes and uplifting employees' motivation by formal and informal support in order to make their organizations more market driven. Since interpersonal connectedness reduces employees 'conflicts and facilitates the development and sharing of market intelligence. It is therefore advisable for senior management to promote the culture of open communication and boundarilessness which could foster organizational effectiveness and sustained competitive edge.

\section{Limitation and Further Research Direction}

From the methodological point of view, the non-probabilistic sample data collection procedure may impose some limitations to the external validity of the findings. Moreover, since it is a cross-sectional data, the results might not be interpreted as proof of a causal 
relationship but rather lending support for the previous causal scheme. As this study was limited to Botswana, it would be interesting to conduct cross-cultural studies in the future in different developing countries for comparison purposes. For future market orientation studies in Botswana, it is suggested that alternative data from documentary sources such as trade and other publications should be used in addition to subjective or perceived data. Another research direction is to probe into the difference of research model in large companies and small and medium sized firms. This could be a very insightful and interesting theme in future research. Another research direction is to explore other tangible and intangible dimensions of management behaviours and environmental dynamics of small service firms in Botswana. Such kind of research can greatly help small firms to adopt appropriate actions and change programs to implement market orientation strategy.

Another limitation associated with this research concerns the context and environment of the study (i.e., Botswana) which limits the generalizability of the findings to other contexts and environments. However, it should be noted that the use of a country outside the traditional research stream of the developed world might be seen as an attempt to increase the scope of the understanding regarding how market orientation is practiced, especially in a developing country (Botswana). This may assist in demonstrating the robustness of the market orientation construct in different environments (developed and developing countries).

Research is also needed in Botswana to explore the complex interrelations of market orientation antecedents and the impact of these on market orientation and performance. Work must now look more deeply into types of centralization, formalization, and other organizational structure effects on market orientation amongst small service firms in Botswana. The relative direction of turbulence (natural disasters, HIV/AIDS pandemic, currency exchange rate, and government regulation) on small service firms may be considered in future research, as well as its effects on market orientation-performance linkage.

Some other interesting directions for future research also spring from this study. One direction relates to the need of constructing a single measurement of marketing orientation that will comprise both the attitudinal and behavioural dimensions of the marketing concept. Such measure would facilitate further research in the field of marketing and specifically the investigation of relationships and or causalities between the adoption of marketing orientation and other managerial considerations. Future research is also needed in order to investigate the conditions under which marketing orientation is developed. Future research should attempt to answer questions like: why does the majority of the companies fail to follow a marketing orientation, especially when the latter is admittedly a solid source of competitive advantage.

\section{References}

Appiah-Adu, K. (1998). Market orientation and performance: Empirical tests in a transitional economy. Journal of Strategic Marketing, 6(1), 25-45.

Atuahene-Gima, K., Slater, S. F., \& Olson, E. M. (2005), The contingent value of responsive 
and proactive market orientation for new product program performance. Journal of Product Innovation Management, 22(6), 464-482.

Aviv. S, Gregory, Rose, and Kropp, F. (2005). Market orientation and performance: a meta-analysis. Journal of Marketing Intelligence and Planning, 23(5), 435-454.

Avlonitis G., \& Gounaris S (1999) Marketing Orientation and its determinants: An empirical analysis. European Journal of Marketing, 33(11), 1003-1037.

Awwad, M. S., \& Agti, D. A. M, (2011), The impact of internal marketing on commercial banks'market orientation, International Journal of Bank Marketing, 29(4), 308-332.

Bamford, C., Dean, T., \& McDougall, P. (1999). An examination of the impact of initial funding conditions and decisions upon the performance of new bank start-ups, Journal of Business Venturing, 15, 253-277.

Blankson, C., \& Cheng, J. M. S. (2005). Have small businesses adopted the market orientation concept? The case of small businesses in Michigan. Journal of business and industrial marketing, 20(6), 317-330.

Burgess, S. M., \& Nyajeka, P, (2007), Market orientation and performance in low-income countries: The case of Zimbabwean retailers. Advances in International Management Journal, 20, 215-257.

Cano, C. R., Carrillat, F. A., \& Jaramillo, F. (2004), A meta-analysis of the relationship between market orientation and business performance:evidence from five continents, International Journal of Research in Marketing, 21, 179-200.

Cervera, A., Molla, A., \& Sanchez. (2001)., Antecedents and Consequences of market orientation in public organizations. European Journal of Marketing, 35(11/12), 1259-1286.

Chelariu, C, Ouattara, A., \& Dadzie, K. Q. (2002), Market Orientation in Ivory Coast:measurement validity and organisational antecedents in a Sub-Saharan African economy, Journal of Business and Indusrial Marketing, 17(6), 456-470. http://dx. doi. org/10. 1108/08858620210442811

Chen, M. \& Miller, D. (1994). Competitive attack, retaliation and performance: an expectancy-valence framework, Strategic Management Journal, 15(2), 85-102.

Dadzie, K. Q, Johnson, W. J., Yoo, B., \& Brashear, T. G. (2002), Measurement equivalence and applicability of core marketing concepts across Nigerian, Kenyan, Japanese and US firms, Journal of Business \& Industrial marketing, 17(6), 430-55.

Dadzie, K. Q., \& Winston, E. (2002), Market orientation of Nigerian and Kenyan firms: the role of top managers. Journal of Business and Industrial Marketing, 17(6), 471-480.

Deshpande, R. (Ed.). (1999). Developing a market orientation. California, Sage publications Inc. 
Dess, G., \& Beard, D. (1984). Dimensions of organisational task environments, Administrative Science Quarterly, 19, 52-73.

Greenly, G. E. (1995). Forms of market orientation in UK companies, Journal of Management studies, 32(1), 47-66. doi:10. 1111/j. 1467-8551. 1995. tb00082. x

Han J. K., Kim. N., \& Srivastava. R. K., (1998). Market orientation and organizational performance: is innovation a missing link. Journal of marketing, 62, 30-45. http://dx. doi. org/10. 2307/1252285

Harris, L. C. (2000). The Organizational Barriers to Developing Market Orientation. European Journal of Marketing, 34(5/6), 598-624.

Harris, L. C., \& Piercy, N. (1998). Management Behaviour and Barriers to Market Orientation in Retailing Companies. The Journal of Service Marketing, 13(2), 113-131.

Horng, S., \& Chen C. (1998). Market Orientation of Small and medium-sized Firms in Taiwan Journal of Small Business management, 36(3), 79-85.

Jaworski, B. J., \& Kohli, K. A. (1993). Market orientation: antecedents and Consequences. Journal of marketing, 7(3), 53-70.

Kirca, A. H., Jayachandran, S., \& Bearden, W. O. (2005). Market orientation: a meta-analytic review and assessment of its antecedents and impact on performance. Journal of Marketing, 69(2), 24-41. Available from: www. emeraldinsight. com (Accessed on 12/09/ 2010). http://dx.doi.org/10. 1509/jmkg. 69. 2. 24. 60761

Kohli, A. K., \& Jaworski, B. J. (1990). Market Orientation: The construct, Research Propositions, and Managerial Implications. Journal of Marketing, 54(2), 1-18. http://dx.doi.org/10. 2307/1251866

Kohli, K. A., \& Jaworski, J. B. (1990). Market orientation: the construct, research propositions and managerial implications. Journal of marketing, 54(2), 1-18. http://dx.doi.org/10. 2307/1251866

Kohli, K. A., Jarworski, J. B. \& Kumar, A. (1993) MARKOR: A measure of market orientation. Journal of Marketing Research, 30(4), 467-477. Available from: http://www. jstor. org/table/3172691 (Accessed on: 10/09/2010).

Kuada, J., \& Buatsi, S. N. (2005). Market orientation and management practices in Ghanaian firms: Revisiting the Jaworski and Kholi framework. Journal of International Marketing, 13(1), 58-88.

Licht, A. N., Goldschmidt, C., \& Schwartz, S. H. (2005). Culture law, and corporate governance. International Review of Law and economics, 25(1), 229-255.

Liu, H., \& Davies, G (1997). Market Orientation in UK multiple retail companies: Nature and Pattern. International Journal of Service Industry Management, 8(2), 170-187. 
Narver, J. C., \& Slater, S. F. (1990). The Effect of a market orientation on business profitability. Journal of marketing, 54 (4), 20-35. http://dx. doi. org/10. 2307/1251757

Narver, J. C., \& Slater, S. F. (1994a). Does competitive environment moderate the market orientation performance relationship? Journal of Marketing, 58(1), 46.

Narver, J. C. \& Slater, S. F. (1994b). Market orientation, customer value, and superior performance, Business Horizons, 37(2), 22.

Nunnally. C. (1978). Psychometric Theory, McGraw-Hill, Publishing, New York.

Pelham, A. M., \& Wilson, D. T. (1996). A longitudinal study of the impact of market structure, firm structure, strategy, and market orientation culture on dimensions of small - firm performance. Journal of the Academy of Marketing Science, 24(1), 27.

Pulendran, S., Speed., R, \& Widing II, R. E, (2000). The Antecedents and Consequences of Market Orientation in Australia , Australian Journal of Management, 25(2), 119-144.

Raaij, V. M. E., \& Stoelhorst, W. J. (2008). the implementation of market orientation - a review and integration of contributions to date. European Journal of Marketing, 42, (11/12), 1265-1293. Available from www. emeraldinsight. com (Accessed on $14^{\text {th }}$ November 2010). http://dx. doi. org/10. 1108/03090560810903673

Rogers, E. M. (1995). Diffusion of innovations (4th ed. ). New York: The Free Press.

Ruekert, R. W. (1992). Developing a market orientation: An organizational strategy perspective. International Journal of research in marketing, 9(3), 225-245.

Sitkin, S. B., \& Pablo, A. L. (1992). Reconceptualizing the determinants of risk behaviour. Academy of Management Review, 17(1), 9-38.

Slater, F. S., \& Narver, C. J. (1994). Does competitive environment moderate the market orientation - performance relationship? The Journal of Marketing, 58(1), 46-55. Available from: http://www. jstor. org/table/3172691 (Accessed on: 10/09/2010).

Smith, P. B., Dugan, S., Peterson, M. F., \& Leung, K. (1998). Individualism-collectivism and the handling of disagreement: International Journal of Intercultural Relations, 22(3), 351-367.

Stokes., \& Blackburn, R. (1999). Entrepreneurship:building for the future, Working Paper Series, Small Business Research Centre, Kingston University, UK.

Voola, R., Casimir, G., \& Haugen, H. (2003). Leadership styles, internal marketing, and market orientation:conceptualizing the relationships, ANZMAC Conference Proceedings Adelaide, 1-7.

Whittington, R., \& Whipp, R. (1992). Professional ideology and marketing implementation, European Journal of Marketing, 26(1), 52-62. 


\section{Macrothink}

Business Management and Strategy ISSN 2157-6068 2013, Vol. 4, No. 2

Winston, E., \& Dadzie, K. Q. (2002), Market orientation of Nigerian and Kenyan firms:the role of top managers, Journal of Business \& Industrial Marketing, 17(6), 471-480.

Wood, V. R., Bhuian, S., \& Kiecker, P. (2000), Market orientation and organizational performance in not for profit hospitals. Journal of Business Research, 48, 213-226.

Zahra, S. A., \& Covin, J. (1993). Business strategy, technology policy and firm performance. Strategic Management Journal, 14(6), 451-478.

Zebal, M. A., \& Goodwin, D. R. (2011). Market Orientation in a Developing Nation-Antecedents, Consequences and the Moderating Effect of environmental Factors. Marketing Bulletin, 22, 1-23. 